Ciência e Natura, Santa Maria, v. 37 n. 42 set-dez. 2015, p. 220-231

Revista do Centro de Ciências Naturais e Exatas - UFSM

ISSN impressa: $0100-8307$ ISSN on-line: $2179-460 \mathrm{X}$

\title{
DIVERSIDADE ARBÓREA E ANÁLISE ESTRUTURAL EM JARDIM INGLÊS DA UNIVERSIDADE DE SÃO PAULO
}

\author{
Flávio Henrique Mendes, Gustavo Torquatro Oliva, Bruna Lara de Arantes, Rafaela Novaes de \\ Abreu, Antonio Carlos Cella, Jefferson Lordello Polizel, Demóstenes Ferreira da Silva Filho
}

Escola Superior de Agricultura "Luiz de Queiroz", Universidade de São Paulo, USP, SP, Brasil.

Resumo

A presente pesquisa objetivou catalogar as árvores do Jardim da Escola Superior de Agricultura "Luiz de Queiroz" (ESALQ/USP), a partir de um banco de dados relacional, a fim de obter informações quali-quantitativas, importantes para a conservação do patrimônio arbóreo e segurança para a população. Foram cadastradas 4867 árvores, pertencentes a 213 espécies e 56 famílias botânicas, com destaque para Fabaceae, Arecaceae, Bignoniaceae e Myrtaceae. As espécies com maior frequência foram: Syagrus romanzoffiana (Cham.) Glassman, Caesalpinia pluviosa DC. e Tabebuia pentaphylla (L.) Hemsl. O indice de diversidade de espécies proposto por Shannon-Wiener foi de 4,44, valor bem satisfatório; contudo, as espécies Rhamnidium elaeocarpum Reissek. (saguaragi), Machaerium nyctitans (Vell. Conc.) Benth. (jacarandá bico de pato) e Trichilia catigua A. Juss. (catiguá) demonstraram potencial invasor, necessitando de manejo para garantir a sustentabilidade e adequação do estilo de Jardim, símbolo da ESALQ.

Palavras-chave: inventário florestal, diversidade de espécies, manejo de árvores.

\section{Abstract}

This study aimed to describe the trees of the Escola Superior de Agricultura "Luiz de Queiroz" (ESALQ/USP) from a relational database in order to obtain qualitative and quantitative information, which is important to the conservation of the arboreal heritage and security of the population. Were registered 4867 trees belonging to 213 species and 56 plant families, especially Fabaceae, Arecaceae, Bignoniaceae and Myrtaceae. The species most frequently were: Syagrus romanzoffiana (Cham.) Glassman, Caesalpinia pluviosa DC. and Tabebuia pentaphylla (L.) Hemsl. The diversity of species index proposed by Shannon-Wiener was 4.44, which is a satisfactory value; however, the species Rhamnidium elaeocarpum Reissek., Machaerium nyctitans (Vell. Conc.) Benth. and Trichilia catigua A. Juss. have demonstrated an attacker potential, requiring management to ensure the sustainability and adequacy of the Garden, an ESALQ mark.

Keywords: forest inventory, diversity of species, trees management. 


\section{Introdução}

A vegetação possui uma importante função na melhoria e estabilidade microclimática devido à redução das amplitudes térmicas, redução da insolação direta, ampliação das taxas de evapotranspiração e amenização da velocidade dos ventos (MILANO; DALCIN, 2000). Dentre outros benefícios da vegetação urbana, verifica-se o controle da poluição do ar, melhoria da qualidade estética, efeitos sobre a saúde mental e física da população, aumento do conforto ambiental, valorização de áreas para convívio social, valorização econômica das propriedades e formação de uma memória e do patrimônio cultural (OLIVEIRA, 1996).

Do ponto de vista conservacionista e prático, é imprescindível o manejo das árvores, por meio de um banco de dados relacional sobre as atuais condições fitossanitárias da população arbórea, sua respectiva localização geográfica e dimensões, uma vez que as futuras ações serão adotadas baseadas nas avaliações técnicas. Os maiores gastos com a arborização urbana são com a manutenção das árvores (TAKAHASHI, 1992).

Inaugurado por volta de 1907, o Parque da Escola Superior de Agricultura "Luiz de Queiroz" (ESALQ/USP) é o único existente no Brasil que possui o Estilo Inglês de Paisagismo, parcialmente preservado. Com uma área de aproximadamente 15 hectares, foi projetado pelo paisagista belga Arsenio Puttemans, ainda em final do século XIX que, pela beleza, raridade e aspectos histórico-culturais, acabou sendo tombado, em 2006, visando à preservação de suas características.

Também é conhecido por "Parque Philippe Westin Cabral de Vasconcellos" desde 1986, representando uma homenagem ao ex-professor e diretor do campus, responsável pela conservação no período compreendido entre 1922 a 1959 (LIMA, 1987).

Entretanto, as linhas de visada do projeto original, característica do estilo inglês de jardim, estão sendo obstruídas pelo crescimento dos maciços. Em 1999, das 10 linhas executadas pelo paisagista, seis encontravam-se interrompidas (BARBIN, 1999).

O cadastro das árvores da ESALQ/USP teve como objetivo catalogar as árvores próximas a prédios, ruas e gramado central, em um banco de dados relacional adaptado de Silva Filho (2002), a fim de obter informações quali-quantitativas, importantes para a conservação das árvores e segurança para a população.

\section{Material e Métodos}

O estudo foi realizado no Parque da Escola Superior de Agricultura "Luiz de Queiroz" (ESALQ/USP), no município de Piracicaba-SP, a $554 \mathrm{~m}$ em relação ao nível do mar, coordenadas geográficas $22^{\circ} 42^{\prime} 30^{\prime \prime} \mathrm{S}$ e $47^{\circ} 38^{\prime} 00^{\prime \prime} \mathrm{W}$. De acordo com o Centro de Pesquisas Meteorológicas e Climáticas Aplicadas à Agricultura (CEPAGRI), o clima é do tipo Cwa, segundo a classificação de Köppen (subtropical úmido com estiagem no inverno), precipitação anual média de $1328 \mathrm{~mm}$ e temperaturas anuais mínima média de $14,8{ }^{\circ} \mathrm{C}$ e máxima média de $28,2{ }^{\circ} \mathrm{C}$ (CEPAGRI). O tipo de vegetação é a floresta estacional semidecidual, localizada no domínio da Depressão Periférica Paulista (OLIVEIRA; PRADO, 1989).

Foram inventariadas as árvores da área urbana, definida como a região aos arredores de prédios, vias públicas e gramado central, com potencial para atingir as vias/prédios caso venham a falhar. $\mathrm{O}$ cadastramento das árvores foi realizado em quatro etapas: 
(i) Plaqueamento: inclusos indivíduos com valor de CAP (circunferência à altura do peito) a partir de 0,15 m; optou-se pelo cadastramento de todas as árvores acima de 0,15 $\mathrm{m}$ de CAP no interior do gramado central, independente se a árvore encontrava-se à beira da rua ou interior, por se tratar de um patrimônio histórico tombado. Utilizou-se martelos, pregos niquelados e placas numéricas (Figura 1), situadas a aproximadamente $2 \mathrm{~m}$ de altura, voltadas preferencialmente para o norte verdadeiro, para padronizar o método e facilitar a visualização dos números de identificação, exceto quando se encontravam em posição de difícil acesso.

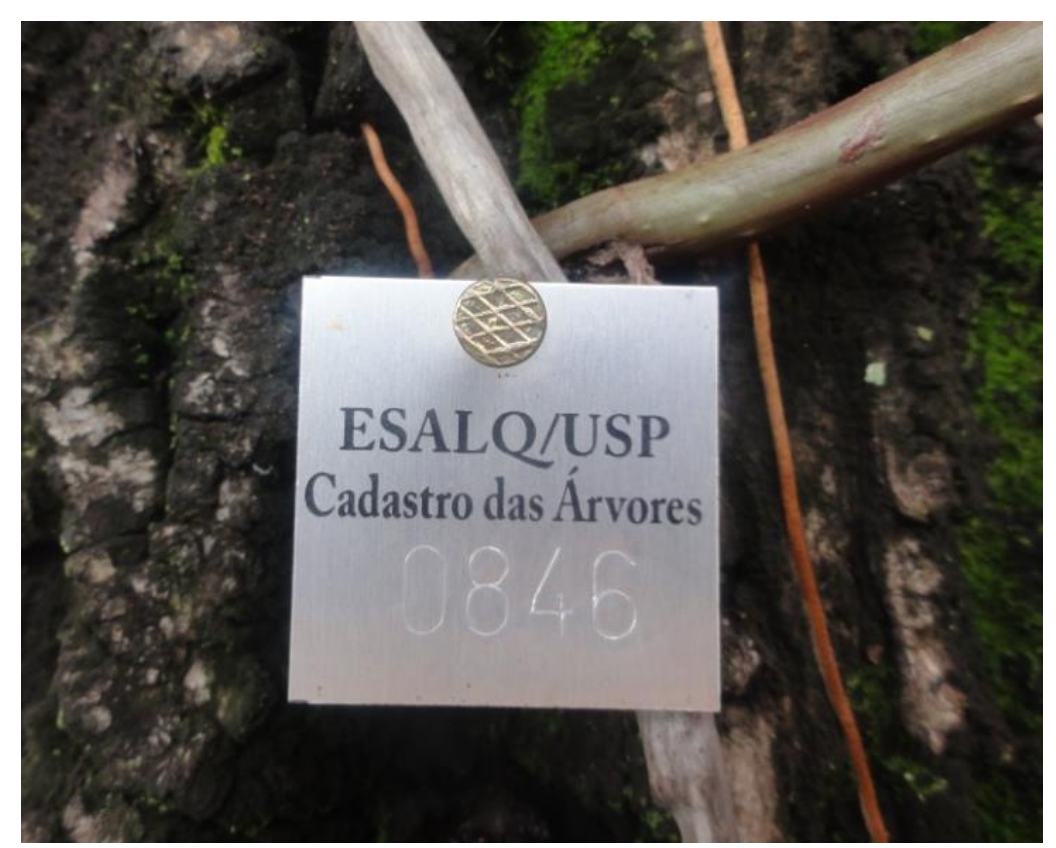

Figura 1 - Placa numerada fixada em jequitibá branco (Cariniana estrellensis).

(ii) Avaliação fitossanitária: foi utilizado o banco de dados relacional feito em MS Access, adaptado de Silva Filho (2002), em Micromobiles Ultra PC do modelo Samsung Q1 (Figura 2), que foram levados a campo para o preenchimento das seguintes variáveis: especificações da espécie, coordenadas geográficas, número da placa e responsável, dimensões, interferências, análise do canteiro, quando presente, e sanidade das raízes, colo, tronco e copa, através da avaliação visual das árvores (VTA - Visual Tree Assessment), método proposto por Mattheck e Breloer (1994). 


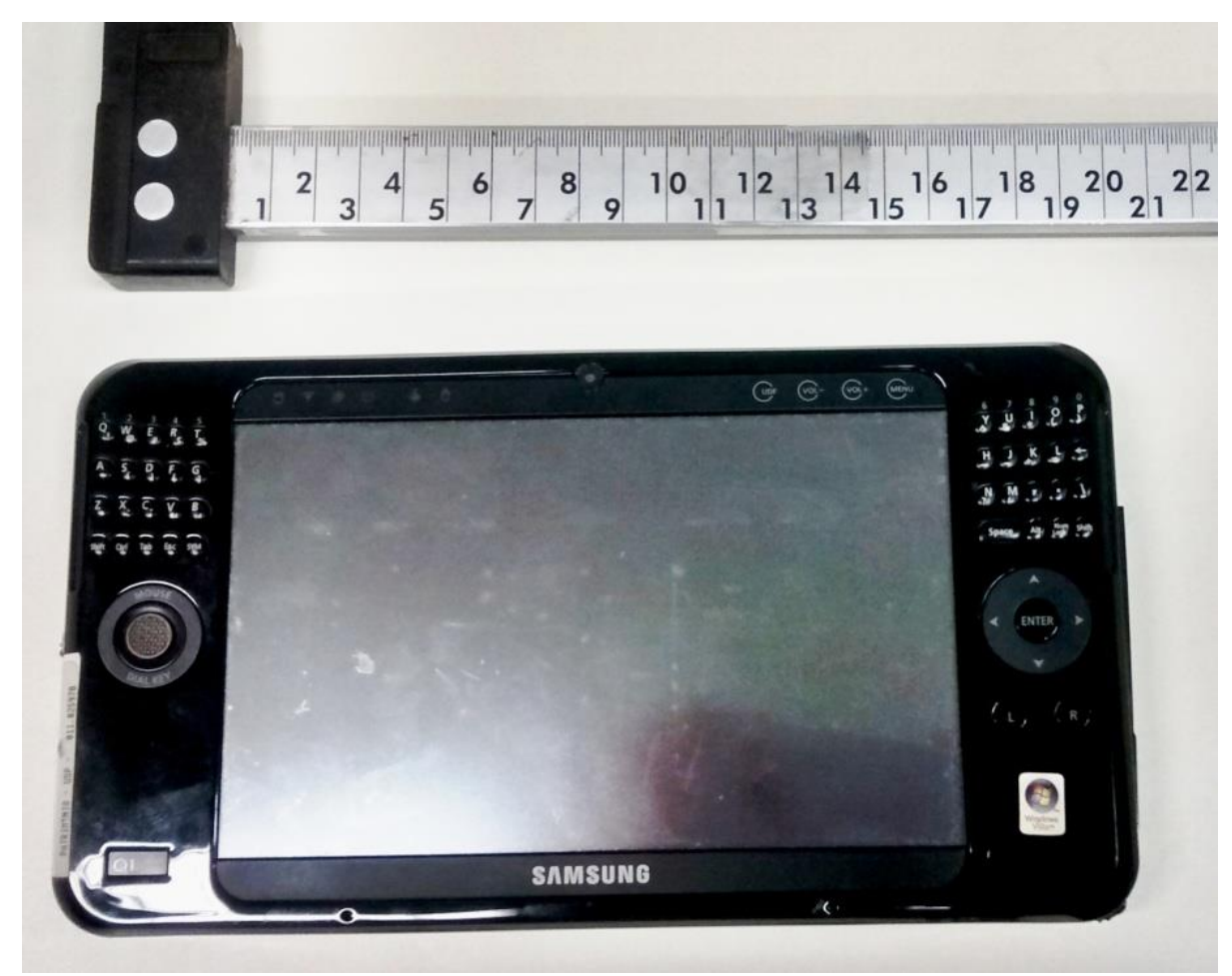

Figura 2 - Micromobile Ultra PC Samsung Q1.

(iii) Medição e fotos: foram coletados dados de CAP e CAP base com fita métrica, diâmetro da copa, altura total do indivíduo e altura da primeira ramificação. Para as análises estatísticas, o CAP foi transformado em DAP (diâmetro à altura do peito), por meio da equação 1:

$$
D A P=\frac{C A P}{\pi}
$$

Onde:

$\mathrm{DAP}=$ diâmetro à altura do peito $(\mathrm{m}) \mathrm{e}$

$\mathrm{CAP}=$ circunferência à altura do peito $(\mathrm{m})$

As fotos foram registradas, no mínimo, duas para cada árvore, sendo uma geral e outra de algum detalhe, como floração, folhagem ou algum dano, através da máquina fotográfica Sony Cyber-shot DSC-HX5V, com resolução de 10,2 megapixels. Na sequência, um flamboyant (Delonix regia) (Bojer ex Hook.) Raf. catalogado (Figura 3): 


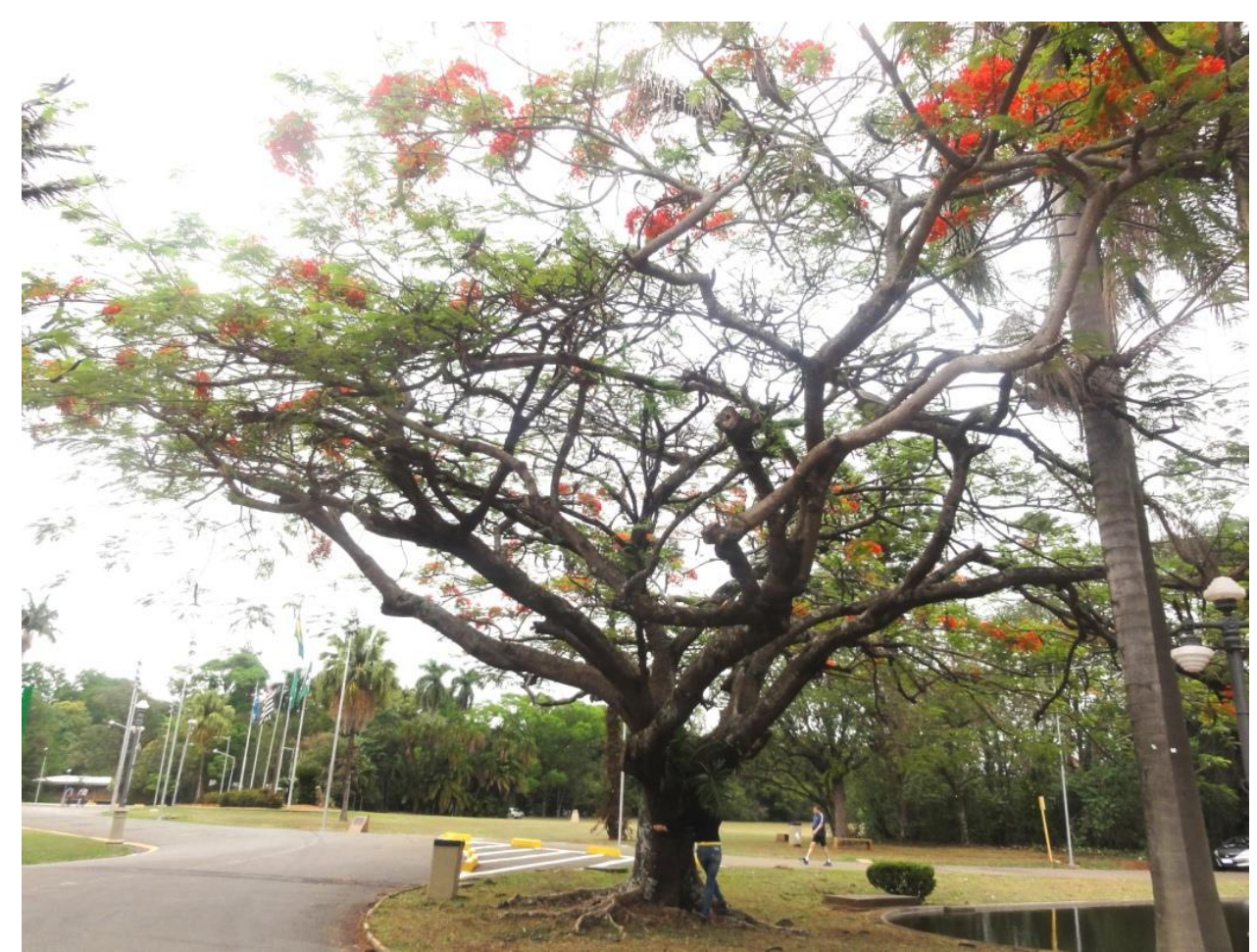

Figura 3 - Flamboyant catalogado no banco de dados das árvores da ESALQ/USP.

(iv) Georreferenciamento: por meio de croquis impressos, as localizações dos indivíduos foram esquematizadas para serem pontuadas no software gratuito Google Earth, a fim de obter as coordenadas geográficas em UTM; o processamento dos dados foi feito no software livre Quantum GIS, na qual as análises estatísticas foram elaboradas no complemento "Group Stats".

No planejamento inicial, a área de estudo foi subdividida em blocos. Primeiro as árvores foram plaqueadas; após, dividiu-se a equipe em dupla ou trio (conforme a necessidade), para ações simultâneas de avaliação, medição, e georreferenciamento. Os dados parciais eram, ao final do dia, reunidos no banco de dados principal (Figura 4).

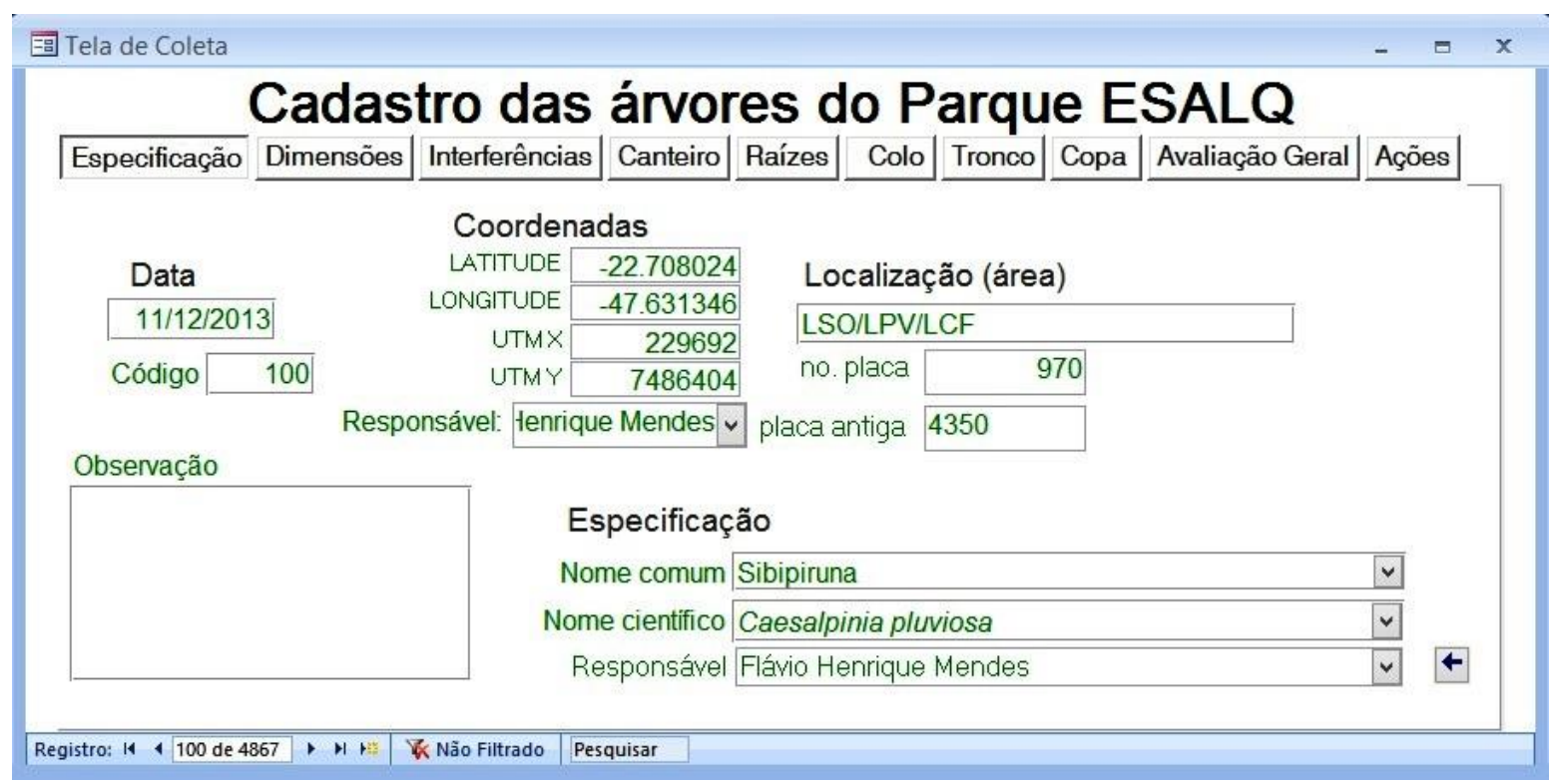


Figura 4 - Banco de dados utilizado para o cadastro das árvores do campus da ESALQ/USP.

\section{Resultados e Discussão}

Foram reconhecidas, avaliadas e geoprocessadas 4867 árvores (Figura 5), de 213 espécies e 56 famílias botânicas.

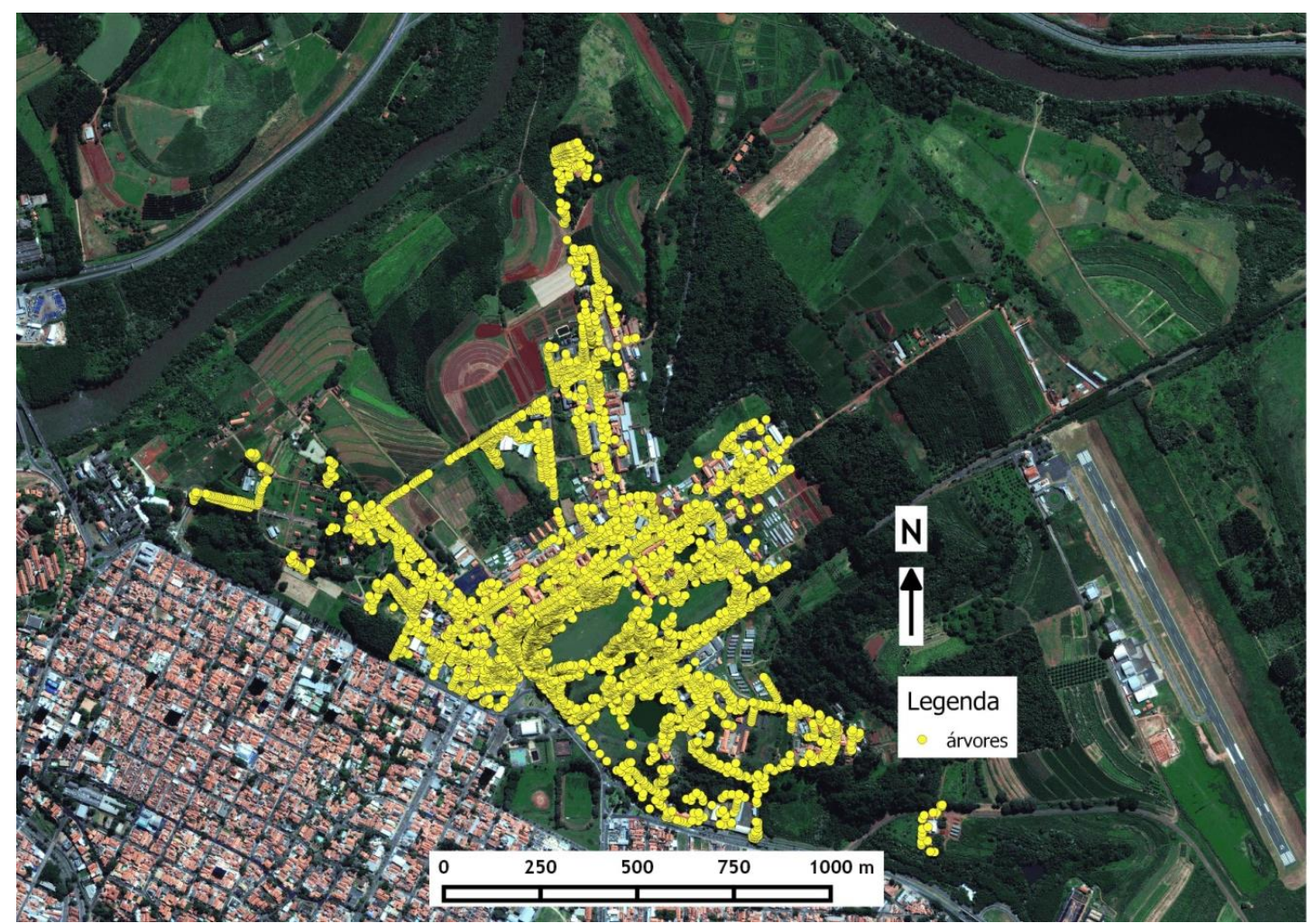

Figura 5 - Árvores do Jardim da ESALQ cadastradas no banco de dados relacional.

O tempo aproximado para a catalogação foi de um ano e meio. Os rendimentos operacionais médios foram:

(i) Plaqueamento: 75 a 100 árvores por hora (equipe de 3 pessoas);

(ii) Avaliação fitossanitária: 7 a 10 árvores por hora por pessoa (sem transcrever medições para o banco de dados) ou 5 a 8 árvores por hora por pessoa (considerando o tempo para transcrição de medições);

(iii) Medição e fotos: 15 a 20 árvores por hora (equipe de 2 pessoas), para coletar informações - número da placa, altura da $1^{\mathrm{a}}$ ramificação, diâmetro de copa, PAP, PAP colo e fotos;

(iv) Georreferenciamento: 20 árvores por hora por pessoa.

Para obtenção da estrutura da comunidade arbórea do jardim da ESALQ foi preciso obter a distribuição das classes diamétricas, frequências de famílias, gêneros e espécies. A figura 6 mostra a distribuição das famílias botânicas. 


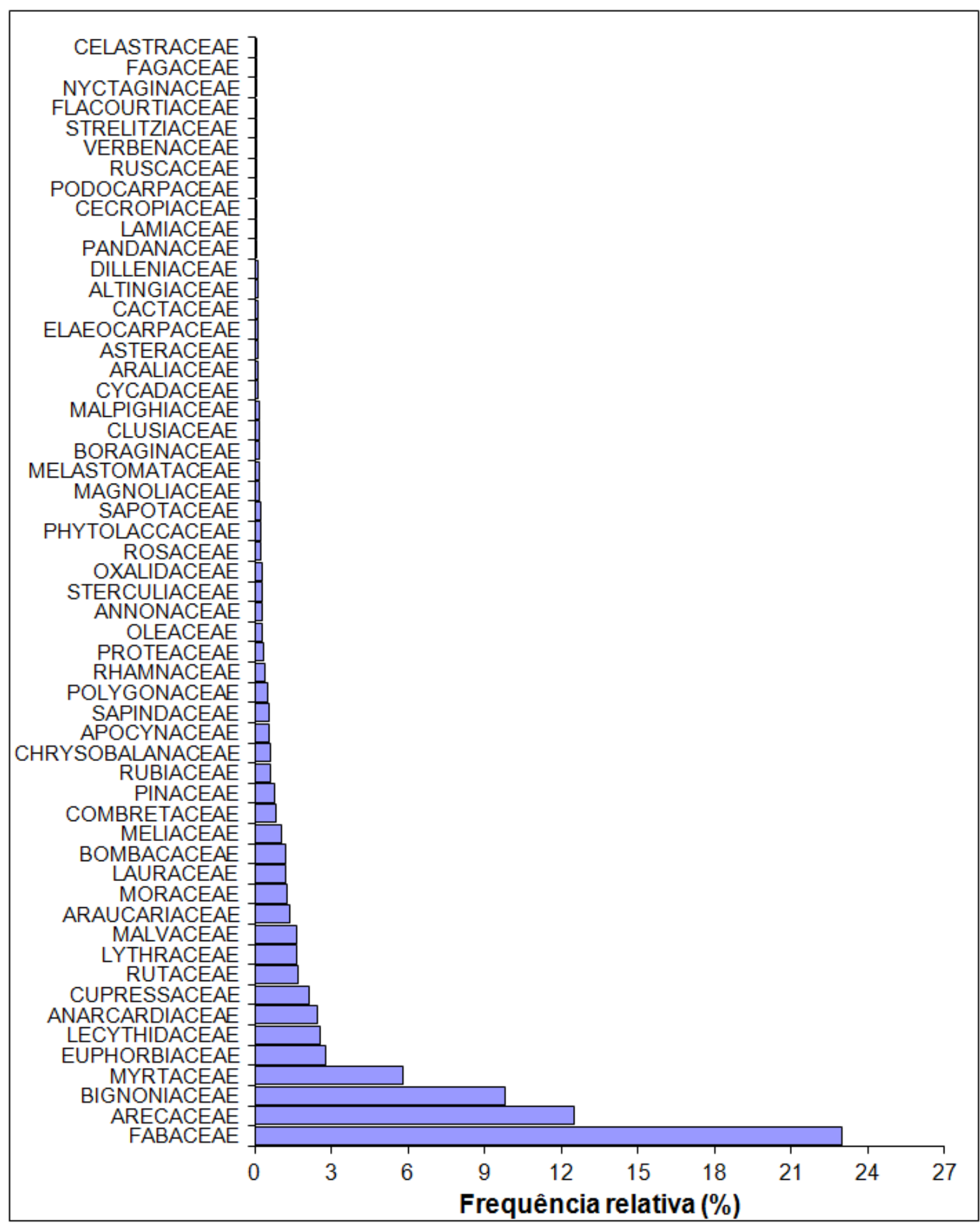

Figura 6 - Distribuição das famílias botânicas com a respectiva frequência relativa.

As quatro famílias de maior representatividade foram: Fabaceae, Arecaceae, Bignoniaceae e Myrtaceae; responderam por mais de $50 \%$ dos indivíduos arbóreos reconhecidos.

Santamour Júnior (1990) recomenda que a população não exceda mais que $10 \%$ da mesma espécie, $20 \%$ do mesmo gênero e $30 \%$ da mesma família botânica, a fim de garantir sustentabilidade da população, por meio da diversidade e, consequentemente, maior proteção contra pragas e doenças. Apesar dos valores seguirem a indicação, é desejável uma 
distribuição mais equitativa entre as famílias, ao passo que nenhum gênero ultrapassou $20 \%$ e nenhuma espécie ultrapassou $10 \%$ de frequência (Figura 7).

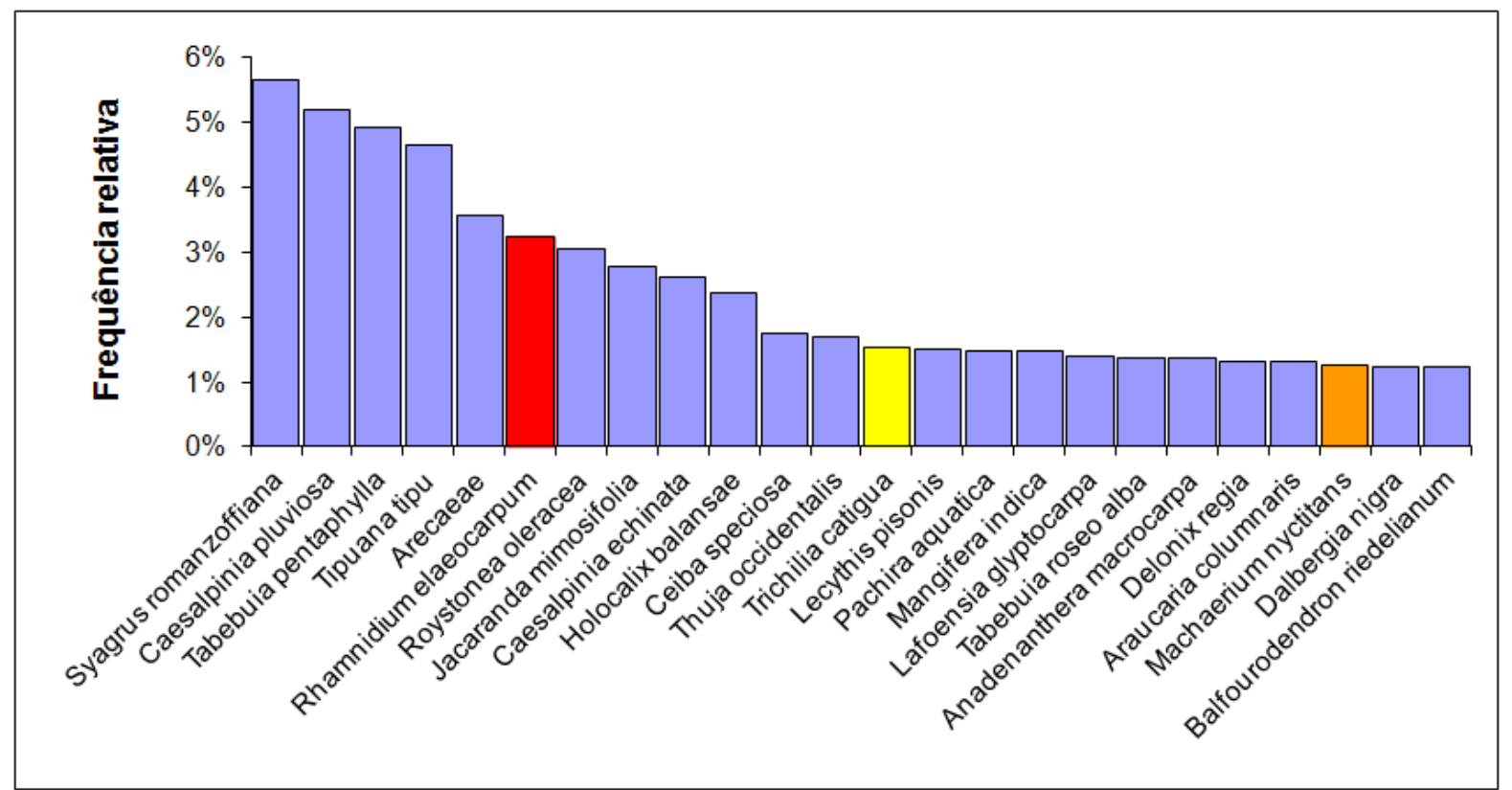

Figura 7 - Espécies em função da frequência relativa, para indivíduos acima de 1\% de frequência; destaques para Rhamnidium elaeocarpum Reissek. (saguaragi), em vermelho, Trichilia catigua A. Juss. (catiguá), em amarelo, e Machaerium nyctitans (Vell. Conc.) Benth. (jacarandá bico de pato), em laranja.

Essas três espécies evidenciadas foram encontradas com grande quantidade de regeneração nas proximidades de árvores adultas e distribuídas ao longo do campus, indicando suposto potencial invasor na população.

Quando se observa a frequência das espécies mais jovens com DAP até 0,15 m (Figura 8), pode-se confirmar esse potencial: juntas, possuem $15 \%$ dos indivíduos jovens, o que pode ser preocupante para um jardim tombado pelo patrimônio histórico, pois altera a configuração original do estilo de Jardim Inglês.

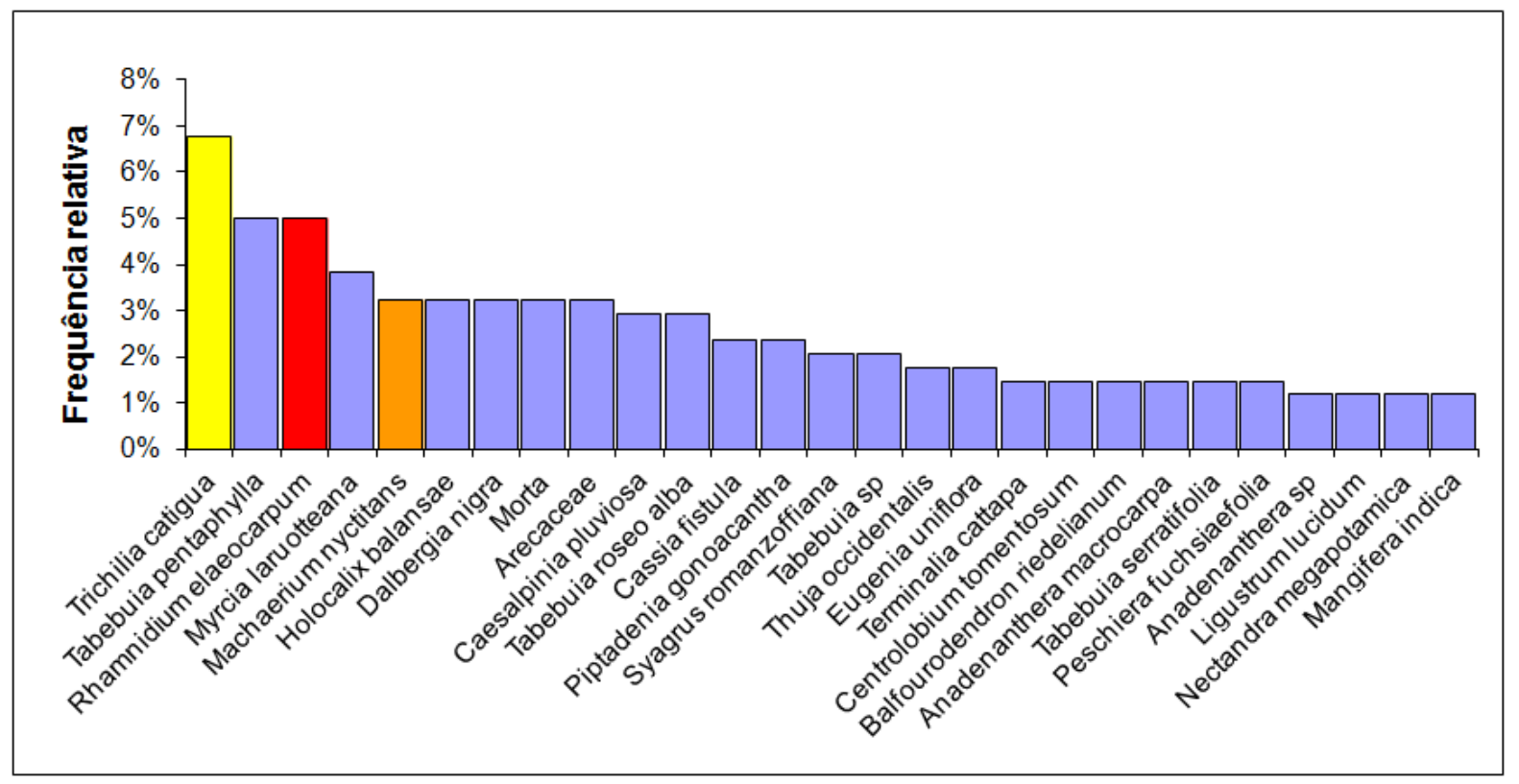


Figura 8 - Distribuição das frequências relativas das espécies com DAP menor que 0,15 m, ressaltando as presenças dominantes de Trichlia catigua A. Juss. , em amarelo, Rhamnidium elaeocarpum Reissek., em vermelho e Machaerium nyctitans (Vell. Conc.) Benth., em laranja.

Na figura 9, tem-se a distribuição de espécies com DAP acima de 0,90 m, representando a distribuição mais antiga do Jardim da ESALQ. Contudo, aparece uma com potencial invasor: Machaerium nyctitans (Vell. Conc.) Benth, que já exibe indivíduos adultos, provavelmente não fez parte do projeto original no Jardim.

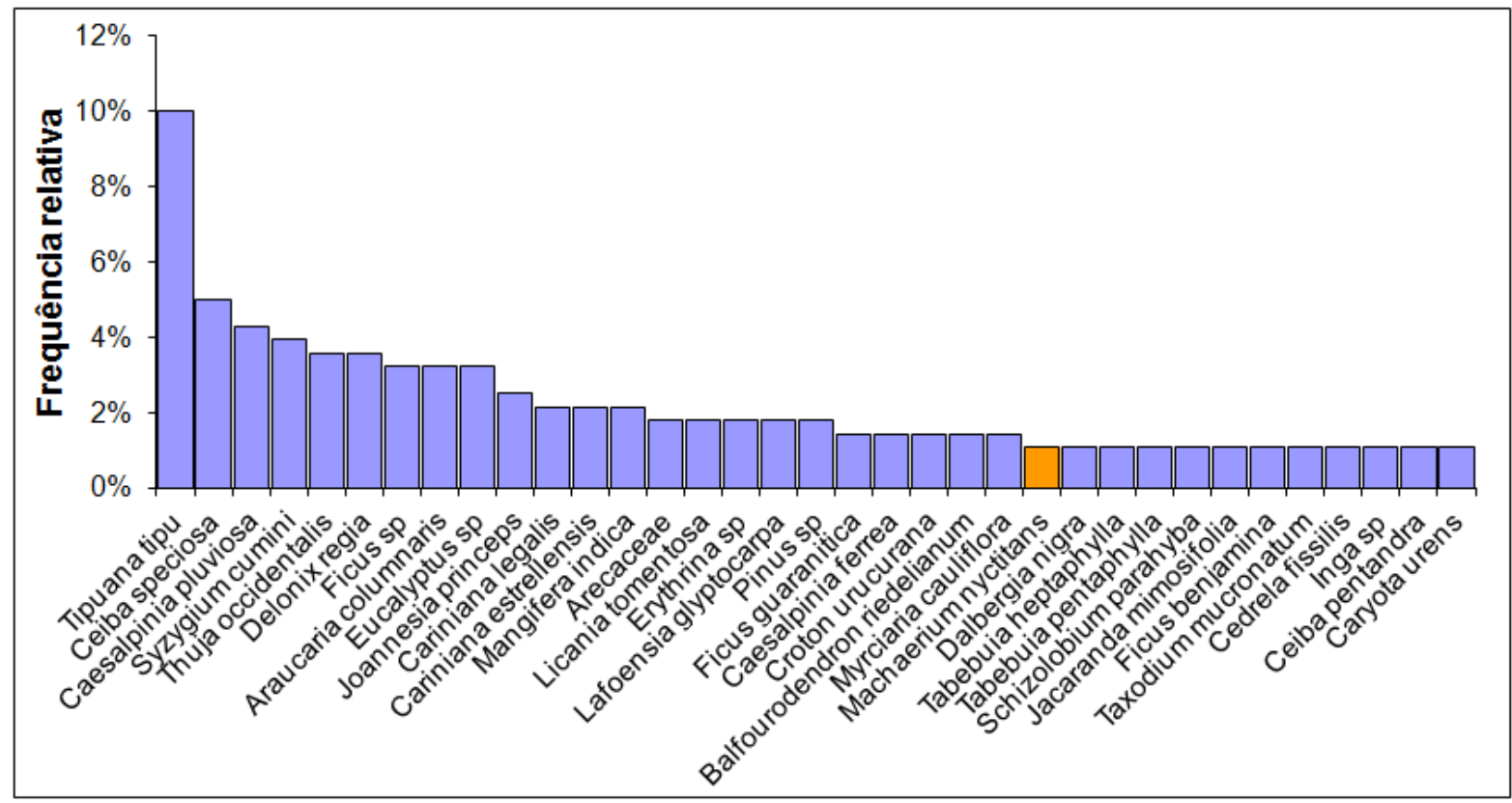

Figura 9 - Distribuição das espécies com DAP acima de 0,90 m, com evidência da presença Machaerium nyctitans (Vell. Conc.) Benth.

Outras espécies podem estar se desenvolvendo, adquirindo características de invasora e descaracterizando a originalidade do projeto paisagístico, o que é muito temerário para a perpetuação do projeto da já centenária Escola Superior de Agricultura "Luiz de Queiroz".

Na figura 10 encontra-se o histograma das classes de DAP, com indivíduos arbóreos concentrados nas classes até $0,30 \mathrm{~m}$ e uma quantidade decrescente à medida que as árvores envelhecem. Para as classes acima de 0,50 m de DAP (1197 árvores) podem sofrer declínio, pois são indivíduos maduros que podem apresentar falhas biomecânicas, tal como sugere o trabalho de (BRAZOLIN, 2009), que analisou a espécie Tipuana tipu (Benth.) O. Kuntze e verificou que a partir de 0,60 m de DAP começavam a cair em São Paulo (SP). 


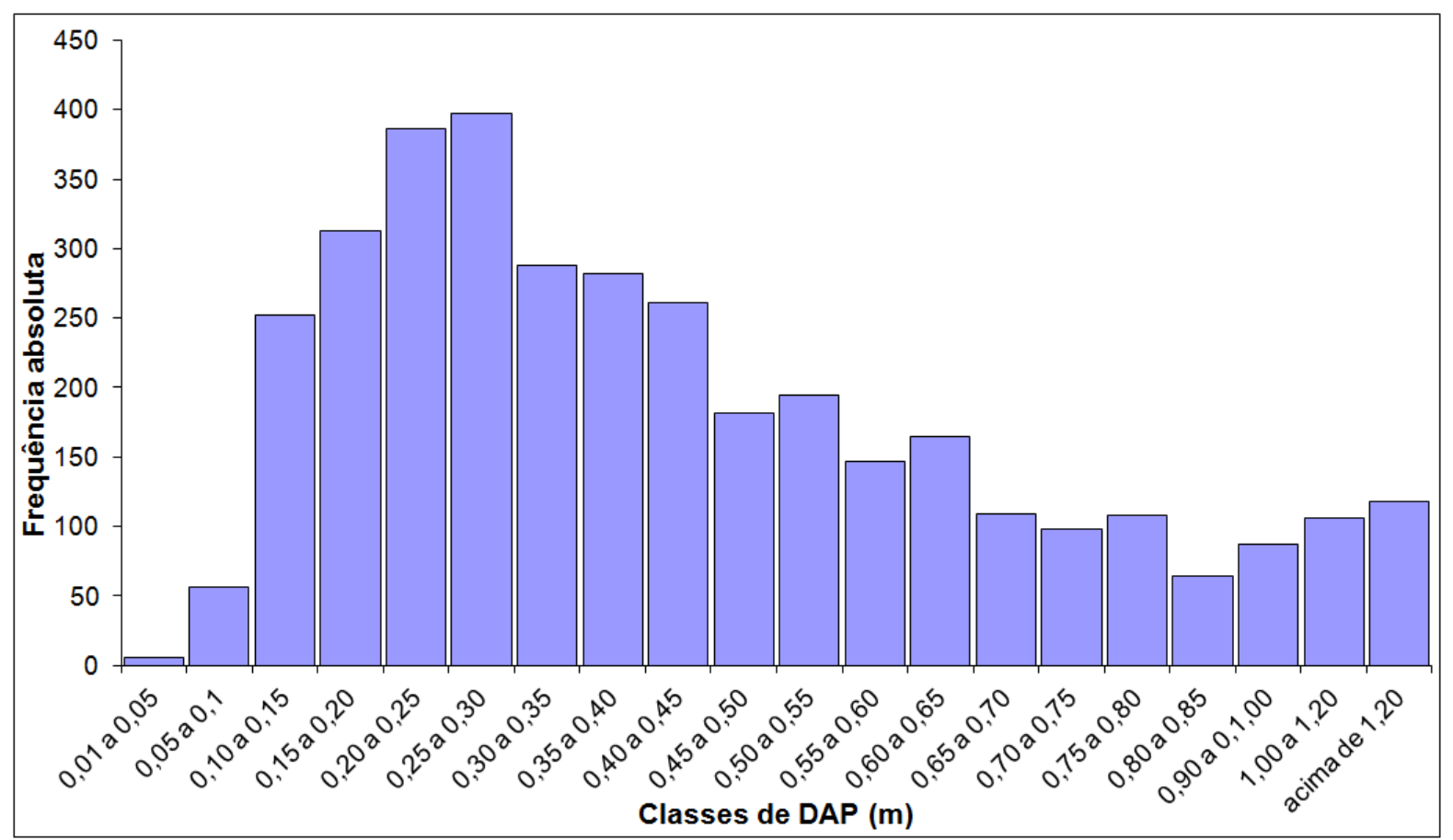

Figura 10 - Classes de DAP em função da frequência absoluta.

Foi calculado o índice de diversidade proposto por Shannon-Wiener $\left(\mathrm{H}^{\prime}\right)$, em 1949, através da equação 2 .

$$
H^{\prime}=-\sum_{i=1}^{S} \frac{n i}{N} \ln \frac{n i}{N}
$$

Onde:

$\mathrm{H}^{\prime}=$ índice de diversidade;

ni = número de indivíduos de cada espécie e

$\mathrm{N}=$ número total de indivíduos

Knight (1975) estipulou que podem ser considerados altos valores entre 3,83 e 5,85 em florestas tropicais. No Jardim da ESALQ obteve-se valor bem satisfatório: 4,44, indicando alta diversidade de espécies.

Quanto à presença de galhos secos e quebrados, as recomendações foram podas do tipo limpeza para 1333 árvores (27,4\%), além de 189 para poda corretiva (3,9\%), 91 árvores para levantamento de copa $(1,9 \%), 39$ para poda de condução $(0,8 \%)$ e 271 para remoção $(5,6 \%)$.

Ainda quanto à avaliação fitossanitária, durante o ano de 2014, foram realizadas muitas escavações na ESALQ para instalação de rede de fios para a iluminação do campus "Luiz de Queiroz". Essa atividade foi impactante nas raízes das árvores e, em trabalhos futuros, recomenda-se avaliar o impacto causado.

\section{Conclusões}

Foi possível catalogar 4867 árvores, de 213 espécies e 56 famílias botânicas. As espécies com maior frequência foram Syagrus romanzoffiana (Cham.) Glassman, Caesalpinia 
pluviosa DC. e Tabebuia pentaphylla (L.) Hemsl., enquanto que as famílias de maior destaque foram Fabaceae, Arecaceae, Bignoniaceae e Myrtaceae.

O índice de diversidade de Shannon-Wiener foi bem satisfatório: 4,44, com boa distribuição de espécies, ao passo que as famílias botânicas poderiam estar mais bem distribuídas, visto que as quatro mais frequentes possuem mais da metade dos indivíduos arbóreos avaliados.

As árvores do Jardim da ESALQ, a partir desse trabalho, devem ser manejadas conforme as informações sobre cada indivíduo, contidas no banco de dados relacional. $\mathrm{O}$ banco de dados deve ter constante atualização para fornecer informações sobre a dinâmica da comunidade arbórea tanto para operações de conservação como para pesquisas na área de Silvicultura Urbana.

As árvores de maior risco devem ser monitoradas por meio de tomografia com frequência regular, sobretudo aquelas que possuem dimensões acima de $60 \mathrm{~cm}$.

É importante que toda a comunidade do campus tenha acesso aos dados; dessa forma, por meio da identificação numérica presente na árvore, é possível consultar as informações referentes a cada indivíduo, sendo interessante tornar público o banco de dados.

Devido aos problemas de escavações junto às raízes, devem-se utilizar tecnologias disponíveis que seja capaz de avaliar os impactos ocorridos e comprometa a segurança das árvores e das pessoas.

O Jardim da ESALQ e suas árvores estão necessitando de urgente intervenção para sua conservação e segurança de toda a comunidade do campus. As espécies Rhamnidium elaeocarpum Reissek. (saguaragi), Machaerium nyctitans (Vell. Conc.) Benth. (jacarandá bico de pato) e Trichilia catigua A. Juss. (catiguá) demonstraram potencial invasor e necessitam de controle; recomendam-se trabalhos futuros que possam analisar minuciosamente a regeneração natural para quantificar outras espécies com potencial invasor no campus.

\section{Agradecimentos}

Os autores agradecem a todos que participaram, direta ou indiretamente, da coleta de dados em campo do Inventário Florestal da ESALQ/USP; ao prefeito do campus da ESALQ, Fernando Seixas; à diretoria da Escola, representada pelo Prof. Dr. José Vicente Caixeta Filho, durante sua gestão nos anos de 2010-2014; à ONG Florespi Socioambiental; e ao Laboratório de Silvicultura Urbana (LSU) pelo suporte dado na execução do referido inventário, pertencente ao Departamento de Ciências Florestais (LCF) da ESALQ/USP.

\section{Referências}

BARBIN, H. S. Estudo das transformações na configuração dos maciços arbóreos / arbustivos do Parque da Escola Superior de Agricultura "Luiz de Queiroz" - Universidade de São Paulo, através de fotografias aéreas verticais e levantamentos florísticos de épocas distintas. 1999. 86 p. Dissertação (Mestrado em Recursos Florestais) - Escola Superior de Agricultura “Luiz de Queiroz", Universidade de São Paulo, Piracicaba, 1999.

BRAZOLIN, S. Biodeterioração, anatomia do lenho e análise de risco de queda de árvores de tipuana, Tipuana tipu (Benth.) O. Kuntze, nos passeios públicos da cidade de São Paulo, SP. 2009. 265 p. Tese (Doutorado em Recursos Florestais) - Escola Superior de Agricultura "Luiz de Queiroz", Universidade de São Paulo, Piracicaba, 2009. 
CENTRO DE PESQUISAS METEOROLÓGICAS E CLIMÁTICAS APLICADAS À AGRICULTURA (CEPAGRI). Disponível em: <http://www.cpa.unicamp.br/outrasinformacoes/clima_muni_436.html>. Acesso em: 10 março 2015.

KNIGHT, D. H. A phytosociological analysis of species-rich tropical forest on Barro Colorado Island, Panama. Ecological Monographs, v. 45, p. 259-284, 1975.

LIMA, A. M. L. P. Nosso Parque faz 80 anos. Revista da ADEALQ, v. 10, n. 6, p. 20-22, 1987.

MATTHECK, C.; BRELOER, H. Field guide for visual tree assessment (VTA). Journal of Arboriculture, Champain, v. 18, n. 6, p. 1-23. 1994.

MILANO, M. S.; DALCIN, E. C. Arborização de vias públicas. Rio de Janeiro: Light, 2000. $226 \mathrm{p}$.

OLIVEIRA, C. H. Planejamento ambiental na cidade de São Carlos (SP) com ênfase nas áreas públicas e áreas verdes: diagnóstico e propostas. 1996. 132 p. Dissertação (Mestrado em Planejamento Urbano e Ecologia Urbana) - Centro de Ciências Biológicas e da Saúde, Universidade Federal de São Carlos, São Carlos, 1996.

OLIVEIRA, J. B. C.; PRADO, H. Carta pedológica semidetalhada do Estado de São Paulo: folha de Piracicaba. São Paulo: Secretaria da Agricultura, 1989.

SANTAMOUR JÚNIOR, F. S. Trees for urban planting: diversity uniformity, and common sense. In: METRIA CONFERENCE, 7., 1990, Lisle. Proceedings... Lisle: 1990. p. 57-66.

SHANNON, C. E.; WIENER, W. The mathematical theory of communication. Urbana: University of Illinois Press, 1949.

SILVA FILHO, D. F.; PIZETTA, P. U. C.; ALMEIDA, J. B. S. A.; PIVETTA, K. F. L.; FERRAUDO, A. S. Banco de dados relacional para cadastro, avaliação e manejo da arborização em vias públicas. Revista Árvore, Viçosa, v. 26, n. 5, p. 629-642, 2002.

TAKAHASHI, L. Y. Monitoramento e informatização da administração e manejo da arborização urbana. In: CONGRESSO BRASILEIRO SOBRE ARBORIZAÇÃO URBANA, 1, 1992, Vitória. Anais... Vitória: PMV/SMMA, 1992. p. 119-124. 